reich, da nach Art. 220 Abs. 1 EGBGB für die Beurteilung von Sachverhalten, die vor dem 1. 9. 1986, dem Tag des Inkrafttretens des IPR-Gesetzes, abgeschlossen waren, das alte Recht anwendbar bleibt. Dies betrifft neben Erb- und Familienrechtsfällen auch alle Arten von Schuldverträgen, sofern das Datum des Vertragsschlusses vor dem genannten Stichtag liegt.

Die zweite Änderung besteht in der Erweiterung des Anhangs. Das Kapitel zum zunehmend wichtiger werdenden Internationalen Öffentlichen Recht wurde neu gef aßt, vor allem die Grundsätze stärker herausgearbeitet. Mit Hilfe der deutlichen Differenzierung zwischen dem Territorialitätsprinzip, wonach Öffentliches Recht grundsätzlich keine extraterritoriale Wirkung entfalten kann, und dem Prinzip der Interessengleichheit, nach welchem eigene und fremde Staatsinteressen in Ausnahmefällen kongruent sind, entwickelt Kegel Maßstäbe für die Anwendbarkeit oder jedenfalls mittelbare Berücksichtigung ausländischen Öffentlichen Rechts. Exemplifiziert werden diese in den kürzeren Abschnitten über Internationales Wirtschafts-, Verfahrens-, Arbeits-, Sozialversicherungs-, Sozial- und Kulturgutrecht, die der Verfasser neu hinzugefügt hat.

Angesichts seiner inhaltlichen Dichte und des Informationsreichtums erübrigt es sich fast, auf den nochmals gestiegenen Umfang des Werkes hinzuweisen. Ein Kurzlehrbuch war es, entgegen dem Namen der Reihe, in der es erscheint, schon bei seiner ersten, 377 Seiten starken Auflage nicht, im übrigen nimmt Kegel Skeptikern selbst den Wind aus den Segeln, indem er mit einer guten Portion Ironie Erklärung und Entschuldigung in Form von Zitaten aus den Vorworten der Vorauflagen liefert, die sich mit diesem leidigen Thema beschäftigen. Wichtiger erscheint es dagegen zu betonen, daß die Darstellung trotz des mittlerweile gut doppelten Umfangs nichts von ihrer Klarheit und Lesbarkeit verloren hat, was nicht zuletzt dem einzigartigen, humorvollen und packenden Stil Kegels zu verdanken ist, der das Lesen zu einem Vergnügen macht.

Annette Flormann

\title{
Dawud Gholamasad
}

Iran. Die Entstehung der "Islamischen Revolution«

Junius-Verlag, Hamburg 1985, 922 S.

Der Verfasser widmet sein Buch der autonomen Arbeiterbewegung im Iran und ihren im Jahre 1983 hingerichteten Vorkämpfern Hadi Kianzad, Mahmud Maschajekhi und Morteza Musavi. Damit wird der politische Hintergrund gekennzeichnet, vor welchem die Entstehungsgeschichte der Islamischen Revolution auf über 600 Seiten Text entwickelt wird.

Der Verfasser stellt insoweit auf den sozial-ökonomischen Zusammenhang ab und führt die Krise des Schah-Regimes als Auslöser der Revolution auf die Krise der im Iran durchgesetzten Kapitalherrschaft zurück, deren einziges Ziel die Integration des Iran in den Weltmarkt gewesen sei. Sein historischer Rückblick verengt den modernen iranischen Staat auf 
eine Funktion des Imperialismus, Aufgabe des Schah-Regimes sei es gewesen, die reibungslose Plünderung der natürlichen Ressourcen zu sichern; dies sei seit dem Ende des 19. Jh. z.B. durch entsprechende Landreformen geschehen. Von dem Eindringen kapitalistischer Elemente in die iranische Landwirtschaft profitierten schließlich alle als Vermittler tätigen Schichten: "Wucherkapital " (man fragt sich nach der volkswirtschaftlichen Zuordnung dieses Begriffs), Handelskapital und Beamte. Angehörige des geistlichen Standes sind Usurpatoren der "wuquf« (der frommen Stiftungen); Armenier, die unter dem SchahRegime gewisse Privilegien genossen (Selbstverwaltung, Steuerbefreiungen) werden als "staatliche Bankiers" und "Vertreter des Wucherkapitals" abgestempelt, ohne daß der Bedeutung und des Schicksals dieser Minorität zur Zeit des Machtwechsels und unter dem derzeitigen Regime Erwähnung getan wird.

Allein das Vokabular zeigt, daß dem Verfasser an einer wertneutralen Untersuchung nicht gelegen ist, er vielmehr die Thematik seines Buches von einer linkstendenziellen Einstellung her angeht. Zitate und Begriffe von Marx und Engels durchziehen den Text und die Anmerkungen, die Einschlägigkeit vieler für das iranische Staatswesen dürfte erheblich in Zweifel zu ziehen sein. So spricht der Verfasser eingangs seines Buches von der Geschichtslosigkeit der iranischen Völker bis zur Entstehung des Kolonialismus und meint damit, daß sie in der Vergangenheit nicht in der Lage gewesen seien, ein kräftiges Staatswesen zu gründen, und daher auch für die Zukunft keine Kraft mehr besessen hätten, ihre nationale Selbständigkeit zu erlangen. Statt vieler sei hier auf das fundierte Buch von Nagel "Staat und Glaubensgemeinschaft im Islam" und namentlich auf das Kapitel "Das Wiedererwachen kämpferischer Elemente in der Schia und die Islamische Revolution" verwiesen. Die zunftähnlichen Verbände zur Safawidenzeit - so der Verfasser - hätten nicht die Interessen des Handwerks und Handels vertreten, sie seien vom Staat abhängige Existenzen, da sie politisch und ökonomisch einen Bestandteil der traditionellen Herrschaftsstruktur bildeten. Dieser Simplifizierung sei das Buch des Orientalisten Taeschner über Zünfte und Bruderschaften im Islam entgegengestellt, in welchem weitaus sachgerechter als durch den Verfasser ein komplexes Bild von Zünften, Orden und Bruderschaften im islamischen Mittelalter gezeichnet wird; das gesamte 5. Kapitel dieses Buches ist der Entwicklung der Futuwwa im Iran der Mongolenzeit gewidmet.

Mehr der politischen Gegenwart und jüngsten Vergangenheit verbunden, untersucht der Verfasser schließlich die ideologischen Strömungen im Iran dieses Jahrhunderts. Er erblickt in allen eine "gemeinsame Aufbruchsbereitschaft zur Herstellung des irdischen Paradieses «, die aus der durch die Modernisierung entstandenen Identitätskrise resultiert. Lediglich in ihren Vorstellungen zur Verwirklichung dieses Ziels unterschieden sich Mujaheddin, Shariatis und Khomeini-Anhänger; ihre Bewegungen reichten vom Reformismus bis zum revolutionären Aktivismus, seien sich aber in ihrer anti-imperialistischen Zielsetzung zur Gewinnung einer neuen Identität einig. Dieses Bündnis habe 1979 schließlich zu einer Einheitsfront gegen den Schah und für Khomeini geführt. Ein durchaus zutreffendes Ergebnis, Denkansätze und Methoden des Verfassers sind jedoch mit Fragezeichen zu versehen.

Dagmar Hohberger 